\title{
COMPONENTS AND RESULTS OF ADOPTED ORGANIZATIONAL INNOVATIONS INSMALL AND MEDIUM ENTERPRISES IN THAILAND
}

\author{
Apiwit Tansoo ${ }^{a}$, Khwanruedee Tuntrabundit ${ }^{b}$ \\ abKhonKaen University, KhonKaen, Thailand \\ Corresponding email: farm401rw@gmail.com
}

\begin{abstract}
The purpose of this research was to demonstrate the components and processes to adopt organizational innovations and results by literatures analyzed and collected data through interviews with the 7 best entrepreneurs of small and medium enterprise from SMEs National Award. By results, there are four components of organizational innovation; Human resource management, Organization structure management, Leadership and Organizational management. The processes are to implement organizational innovation in order to actualize the initial vision of trends and business analysis which is the fundamental basis. Then, targets will be set and organizational innovations will be adopted. Brainstorming was implemented to resolve problems, and ways of implementation stages are from the result which found that operational performance, employee encouragement, and organizational performance increased after used organizational innovation.
\end{abstract}

Moreover, entrepreneurs can use researched results to develop organizational innovation in their organizations for achieving their goals and sustainable development. Furthermore, researched results were used to develop questionnaires to measure components of organizational innovation obviously.

Keywords: Organizational Innovations, Small and Medium Enterprise in Thailand.

\section{Introduction}

Rapid changing of Economic environment nowadays is the keys of changing and acquiring business success. Intangible asset was used to create differences in business operation. One of the keys is known as innovations (Wong, 2013). It was applied by using ideals, behavior, system, policy, program, instruments, products and services to create innovations in organization(Mothe \& Thi, 2010). OECD (2005) divided innovation into four categories covering changes in the organization's various activities in the manufacturing and service industries. They can be classified as follows:1) Product innovation involves development, designing new products or services to market, 2) Process innovation involves changing processes and services for customers, 3) Marketing innovation involves changes in product design, packaging, promotion, product location, and product pricing, and 4) Organizational innovation is a new way of operating in an organization, style in the workplace, or building relationships outside the organization. From the above classification, it can be seen that innovation is not limited to product development and manufacturing, but also includes the organizational structure, management process and marketing change[4].

In the past, researchers focused on technological innovation Soltani \& Hosseini, (2012), but the interest of non-technological innovation was increased in the presentCamison \&VillarLopez, (2014), because an aspect of innovation studied only in technological innovation was not enough and it became narrowed. It is quite hard for an organization to compete with any competitors by using only technological innovation or process innovation, because it is easy to imitate. So, organizational innovations opted to use the current (Ganter \& Hecker, 2014; 
Baba, 2012). It is the key of organization development that leads an organization to create sustainable competitive advantage(Camison \& Villar-Lopez, 2014). Additionally, it is the reason to increase organizational performance (Jimenez-Jimenez \& Sanz-Valle, 2011).

From Researchers and literature reviews, there were less numbers of organizational innovation studies. Some researchers developed measure instruments, but it could not be classified components of organizational innovations completely (Ganter \& Hecker, 2014; Camison \& Villar-Lopez, 2011; Camison \& Villar-Lopez, 2014; Crossan \& Apaydin, 2010). Additionally, the tools used to measure organizational innovation are also different in each research and have not covered all dimensions of organizational innovation(Armbruster, et al., 2008). This may be due to the lack of studies on the number and nature of components of organizational innovation. If researchers are studying the components of organizational innovation in a variety of contexts, it would help make a conclusion on the components of organizational innovation and create a deeper understanding. To compete in all dimensions of organizational innovation, Studies of organizational innovation components and adaptation is important and more beneficial, and it could be concluded in components of organizational innovation and could be understood deeply to adopt organizational innovations promptly.

\section{Literature Review \\ 2. Organizational Innovation 2.1 Definition}

There has been a variety of perspectives on the definition of organizational innovation. There has still not been any well-accepted and comprehensive definition of organizational innovation in past researches. Researchers have developed definitions of organizational innovation in their own context and try to understand the complex phenomena of organizational innovation based on their own insights (Armbruster, et al., 2008). However, there are similarities among definitions of organizational innovation from the past to the present. For example, organizational innovation is the use of organizational management methods, operational concept, operational control, and design or change organizational structure. These definitions reflect new perspective on intra-organizational management in the aspects of human resources management, organizational strategy and operational control that are relevant to inter-organizational, which is a new process that is beyond the scope of the organization's knowledge such as collaboration between organizations and business partnerships (Camison \& Villar-Lopez, 2014).

From literary and research on organizational innovation review, the definition of organizational innovation can be concluded to refer to the new way of doing things related to the management process of the organization, organizational structural change, and human resource management that is a new thing in the organization and creates value for the organization.

\subsection{Organizational Innovation Components and Indicators}

From components and indicators of organizational innovation related literature reviews, it was found that some researchers have created indicators, but have not classified organizational innovation components. On the other hand, some researchers have created indicators and classified organizational innovation components for the measurement to cover the concept of organizational innovation more. Organizational innovation components are required to be clearly distinguished because each organizational innovation component differently affects the organization performance (Armbruster, et al., 2008).

The measurement and classification of organizational innovation components in past researches is vague and redundant. Many indicators are included in the composition of many organizational innovations. For example, employee rewarding has been classified in both the business relationship within the organization and organizational management. Additionally, 
organizational structural changes and employee recruitment are also included in many organizational innovation components, etc.

Additionally, the components of organizational innovation from past researches have not covered all organizational innovation concepts. One example is the OECD, (2005)measurement which is an organizational innovation measurement tool that has been used by many researchers. If the dimensions of organizational innovation components in strategic planning, organizational structure, and human resources management are added, the measuring instrument will be more comprehensive. Moreover, the creation of measurement tools of innovation organizations are still lacking. Therefore, it is necessary to develop a measurement tool for organizational innovation to provide the most comprehensive organizational innovation measurement tools (Armbruster, et al., 2008).

\section{Objective}

Searching for components, adaptation and results of organizational innovations in small and medium enterprises in Thailand.

\subsection{Methodology}

This research was gathered from qualitative data collection from studying phenomenal and experiences of 7 entrepreneurs in small and medium enterprises awarded from SMEs National in Thailand, 2012 - 2015. The interactions with 7 outstanding entrepreneurs from different industrial fields was indeed great, as they were pleased to release their business information in an interview by using completely researched instruments including notebook for fieldwork, sound recording device, and structure interview form created with secondary data which was studied from notions, theories, and researches in field of various topic. In the structure interview form, all questions were open-end questions for research participants could show their precise ideas independently. Then, data would be decrypted in words and grouping all analyzed results. After that, all information was sent back to research participants to ensure or adding any new data until information is completed.

\section{Results}

From the results, it was found that components of organizational innovation and used adaptation in organizations are as follows;

\subsection{Components of Organizational Innovation}

There were 4 important keys of organizational innovations, and it was praised and demonstrated that is different from the past by behavior and activities.

\subsection{Human Resource Management}

Obviously, behavior and activities are an ordering progressive way in a career path. Inside and outside training for expert in their career skills and could be developed continuously, support for continuous education and researching for developing and improving products. The important activities are showing creativity ideas independently, having authority to determine their assignment, collaborating in implementation stage, and brainstorming for planning and solving problems in organizations. Moreover, finding ways to modify and implement stages to develop organizations by following guidelines of implementation in every stages is considered important. Then, benefits and praising good employees to motivate them when task are achieved, collaborating activities between employees and organizations for creating good relationship, and making employees to feel like their families are all important keys.

\subsection{Organization Structure Management}

Organization structure is a flat organization and more closely for giving direct suggestion to every structure levels, and it is emphasized to create good environment and to promote organization value and culture. 


\subsection{Leadership}

Entrepreneurs could find business opportunities all time and have to plan business strategies. Moreover, they could study continuously by attending various training programs to motivate themselves and enabling them to adapt business implementation rapidly in present business environment.

\subsection{Organization Management}

IT system has been brought to help in organization management such as accounting, customer data collected, inventory management etc. An Online system is used for internal communication in organization, increased marketing channel, and customer services. Introducing lean management could help to depress defects and implementation steps. There are competitive analysis processes to emphasize creation of innovation products, improve employee evaluation process, and customer satisfaction data was collected to improve operational process. In addition, guidance and counsel from professional experts outside an organization could be used to help in any direction, and joining evaluation that includes awards could promote and develop the limited of organization management.

\subsection{Processes of Organizational Innovations Applied and Results.}

The result reveals that organizational innovations were adopted by entrepreneurs. They began from foresight about rapidly changing tendencies. So, new ideals were applied in modifying an organization for suitable situation in present. Then, setting targets and finding suitable organizational innovations achieved organization goals by using new management methods from studies and training, choosing suitable methods for an organization. Problems were reviewed and brain storming to find means of solving problems. Organizational innovations were applied to increase efficient operational in an organization. After organizational innovations in an organization were adopted, operation cost was decreased and all department operations were increased and it affected every part of an organization. Moreover, it could motivate staffs to work better and happy, and increase organizational performance.

\section{Conclusion and Implications}

Organizational innovations were used by applying concepts, behavior, system, policies, and implementation processes for creating organization value including four components; Human resource management, organization structure management, Leadership, and Organizational management. These are keys used for adopting organizational innovation; Foresight about tendency and environment of business, setting goals for adopting organizational innovations in organization that was archived from learning and training and brainstorming to find problem and solving methods to improve operation in an organization. It was found that working performance was increased after adaptation of management processes, and staffs were happy and had more courage to work. Moreover, organizational performances were increased after using new management methods.

This study explained the understanding of organizational innovation. From contexts of small and medium enterprises in Thailand, results were used in helping entrepreneurs to develop suitable organizational innovation to create sustainable competitive advantage and to achieve their goals. Furthermore, knowledge of organizational innovation was expanded in academic fields. Researchers envisioned important topics for the future use. Data will be used to develop questionnaires and finding components of organizational innovations by statistical analysis methods to accurately measure instruments and to cover concepts of organizational innovations. 


\section{References}

i. Armbruster, H., Bikfalvi, A., Kinkel, S. \& Lay, G., 2008. Organizational innovation the challenge of measuring non-technical innovation in large-scale surveys. Technovation, Volume 28, pp. 644-657.

ii. Baba, Y., 2012. Adopting a specific innovation type versus composition of different innovation types. International Journal of Bank Marketing, 30(3), pp. 218-240.

iii. Camison, C. \& Villar-Lopez, A., 2011. Non-technical innovation: organizational memory and learning capabilities as antecedent factors with effects on sustained competitive advantage. Industrial Marketing Management, Volume 40, pp. 1294-1304.

iv. Camison, C. \& Villar-Lopez, A., 2014. Organizational innovation as an enabler of technological innovation capabilities and firm performance. Journal of Business Research, Volume 67, pp. 2891-2902.

v. Crossan, M. M. \& Apaydin, M., 2010. A multi-dimensional framework of organizational innovation: a systematic review of the literature. Journal of Management Studies, 47(6).

vi. Ganter, A. \& Hecker, A., 2013. Deciphering antecedents of organizational innovation. Journal of Business Research, Volume 66, pp. 575-584.

vii. Ganter, A. \& Hecker, A., 2014. Configurational paths to organizational innovation qualitative comparative analyses of antecedents and contingencies. Journal of Business Research, Volume 67, pp. 1285-1292.

viii. Jimenez-Jimenez, D. \& Sanz-Valle, R., 2011. Innovation, organizational learning, and performance. Journal of Business Research, Volume 2011, pp. 408-417.

ix. Mothe, C. \& Thi, T. U. N., 2010. The link between non-technological innovations and technological innovation. European Journal of Innovation Management, 13(3), pp. 313-332.

$\mathrm{x} . \quad \mathrm{OECD}$, 2005. The measurement of scientific and technological activities - proposed guidelines for collecting and interpreting technological innovation data, Paris: OECD.

xi. Soltani, S. \& Hosseini, S. J. F., 2012. Key factors influencing organizational innovation in small rural food industried: case study of Iran. African Journal of Business Management, 6(9), pp. 3553-3561.

xii. Wong, S. K. .. S., 2013. The role of management involvement in innovation. Management Decision, 51(4), pp. 709-729. 